\title{
End-stage renal disease patients up nearly $19 \%$
}

The number of patients being treated for end-stage renal disease (ESRD) has risen from 13.3 per 100000 in 1997 to 15.8 per 100000 in 2001, an increase of $18.8 \%$ in 5 years, according to the Canadian Institute for Health Information (CIHI).

Not only did the number of ESRD patients increase, but so did their age. The number who were 65 or older went up $33 \%$ during this period. As of 2001, $55 \%$ of new patients being treated for ESRD were 65 or older. The percentage of older t women in this group increased by $45 \%$, compared to an increase of $23 \%$ among men. Men, however, still accounted for $58 \%$ of ESRD patients in 2001.

In 2001, 3\% of new ESRD patients received a pre-emptive kidney transplant as their first

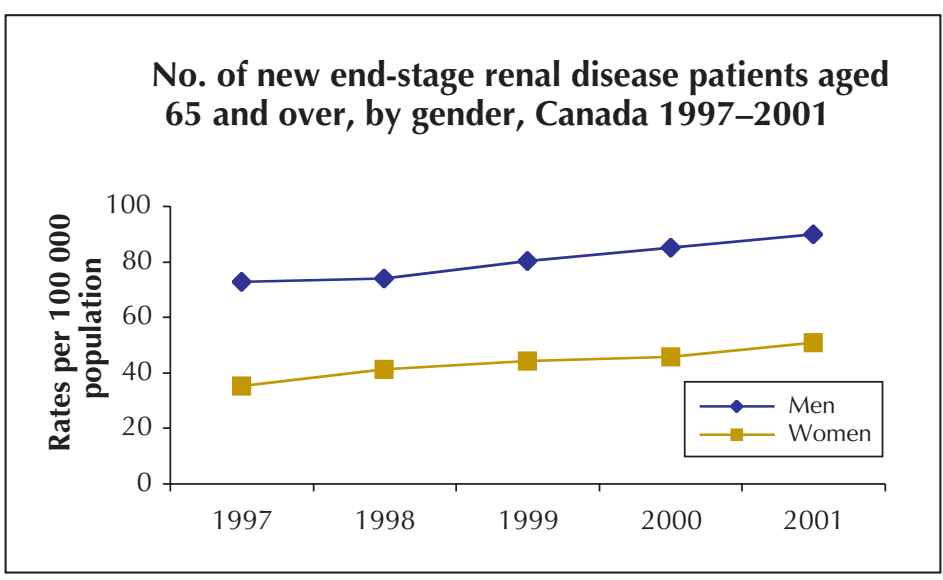

ESRD therapy, and $75 \%$ started hemodialysis. Nearly 16000 Canadians were receiving dialysis at the end of 2001.

The percentage of cases in which diabetes was the primary cause of ESRD increased from $29 \%$ in 1997 to $33 \%$ in 2001 .
Among ESRD patients aged 65 years and older, $30 \%$ were diagnosed with diabetes as their primary cause of kidney failure in 2001, up from $25 \%$ in 1997. - Tara Chauban, Research, Policy and Planning Directorate, CMA

\section{INFECTIOUS DiseAse}

\section{UK patient first to contract vCJD via blood transfusion}

The death of a patient in the UK from variant CreutzfeldtJakob disease (vCJD) is very likely the first documented transfusion-related transmission, The Lancet has reported.

The unidentified patient received blood during surgery in 1997, showed symptoms of vCJD in late 2003 and died in December. The donor of the blood fell ill with the brain-wasting disease in 1999 and died soon afterwards.

Although it is possible both individuals acquired the disease separately, The Lancet reports that it is unlikely (2004;363:417-21). The transfused patient was much older than the average person who dies of vCJD: 69 versus 30 . This, and an examination of $\approx$ blood donation records, led the researchers to conclude that the odds of the disease not being acquired via a transfusion were about 1 in 30000 .

In another study (The Lancet 2004;363:422-8), the department of medical research at the French
Atomic Energy Commission reported that the macaque monkey can be infected with bovine spongiform encephalopathy (BSE) orally or intravenously.

They concluded that blood transfusion should be regarded as a "likely route of contamination for vCJD patients with a medical history involving a transfusion during the period of risk [1980 to 1996]."

Variant CJD is an incurable, degenerative brain disorder normally associated with eating meat infected with BSE.

The news of the transfusion case "created quite a stir" at Canadian Blood Services (CBS), said Medical Director Dr. Heather Hume. However, CBS has stringent donor exclusion measures in place that "we believe are sufficient," said Hume.

First introduced in 1999, CBS travel exclusions now rule out potential donors who have spent 3 months or more cumulatively in the UK or France, or 5 years or more in Western Europe since 1980 . In addition, donors who have received a blood transfusion in the UK since 1980 are barred from donating.

As a result of these restrictions, CBS has lost 5\%-6\% of its donors. "There aren't any additional measures we could take, in the absence of a test," said Hume.

The US Food and Drug Administration (FDA) has similar donor criteria while HémaQuébec's rules are even more stringent, excluding donors who have spent 30 days in the UK or France; or 6 months in Western Europe.

The US Office of Blood Research and Review announced in February that it would re-evaluate its donor policy, even though current measures now eliminate $90 \%$ of the overall risk.

"The new case in England has caused shock waves around the globe," noted FDA spokesperson Lester Crawford. - Barbara Sibbald, CMAJ 